\title{
Effect of Ion Currents on the Morphology of Focused Ion Beam Milled Patterns on a Single Crystalline Diamond
}

\author{
W. I. Lee*, R. Golnabi*, A. Calabro*, C. Queenan*, D. Becker*, and D. Kim* \\ * Bergen County Academies, 200 Hackensack Avenue, Hackensack, NJ 07601
}

Various innovative applications of diamonds, including spintronics, field emission, and bio-sensing, have been studied in recent years [1]. In most cases, these applications require the precise pattering of diamonds, which is not trivial due to diamond's structural hardness. Among various patterning techniques, the focused ion beam (FIB) milling method has been proven to provide flexibility as well as high resolution in the pattern design [2]. However, re-deposition of both the milled carbon and $\mathrm{Ga}^{+}$ions from the FIB and nano-terracing ("ripple") effects disrupt clean milling patterns [3]. Most importantly, the morphology of such patterns depends significantly on the applied ion current.

The (110) single crystalline diamond was sputtered with a thin layer gold before milling (FEI Quanta 3D 200i Dual Beam). The ion beam source was $30 \mathrm{kV} \mathrm{Ga}^{+}$. The elemental analysis was carried out with Oxford Instruments energy dispersive X-ray spectroscopy attached on the dual beam machine.

The patterning of overlapping lines (Figure 1a) with the ion current of $20 \mathrm{nA}$ showed that for a 1 $\mu \mathrm{m}$-wide line, the ripple effects reach approximately $2 \mu \mathrm{m}$ outward each side. Moreover, the milling of a new line pattern over an existing milled line resulted in the refilling of previously etched lines by re-deposition. High ion current of $20 \mathrm{nA}$ results in many deformation of designated pattern although it has high milling rate. Elemental analysis (Figure 1b) on the re-deposited area revealed gallium enriched carbon (6\% gallium and $94 \%$ carbon).

To further investigate the effects of ion current on the pattern morphology, the same pattern with was milled with different ion current (3, 7 and $20 \mathrm{nA}$, Figure $2 \mathrm{a}, 2 \mathrm{~b}$ and $2 \mathrm{c}$ respectively). The triangular pattern had designated dimensions of $2 \mu \mathrm{m}$ base by $1.5 \mu \mathrm{m}$ height and a depth of $20 \mu \mathrm{m}$. Analysis on the images revealed the correlation between the milled size and ion current. The bottom area of the milled diamond appears to saturate at $7 \mathrm{nA}$, while the top surface area continues increasing linearly. It is possible that increased re-deposition at higher currents negates additional milling at the bottom surfaces. As the current increased, the milled geometry became progressively more circular in form. Moreover, substantial nano-terracing became visible as the current was raised (Figure 2c). Further studies were conducted with square patterns $(2 \mu \mathrm{m}$ x $2 \mu \mathrm{m}$ x $20 \mu \mathrm{m})$ showed similar results (Figure 2d, e, f). These results suggest that the best pattern accuracy can be obtained with lowest ion current at the expense of milling rate.

\section{References}

[1] M. W. Geis et al., Appl. Phys. Lett. (1996) 67 1328-1330.

[2] Steve Reyntjens et al., J. Micromech. Microeng. (2001) 11 287-300.

[3] A. Datta et al., Phys. Rev. B. (2001) 64125407.

[4] The authors would like to acknowledge Prof. Glen Kowach at the City College of New York for his advice and for providing the (110) diamond used in this research. We also thank the administration of the Bergen County Technical Schools District for their continued support. 

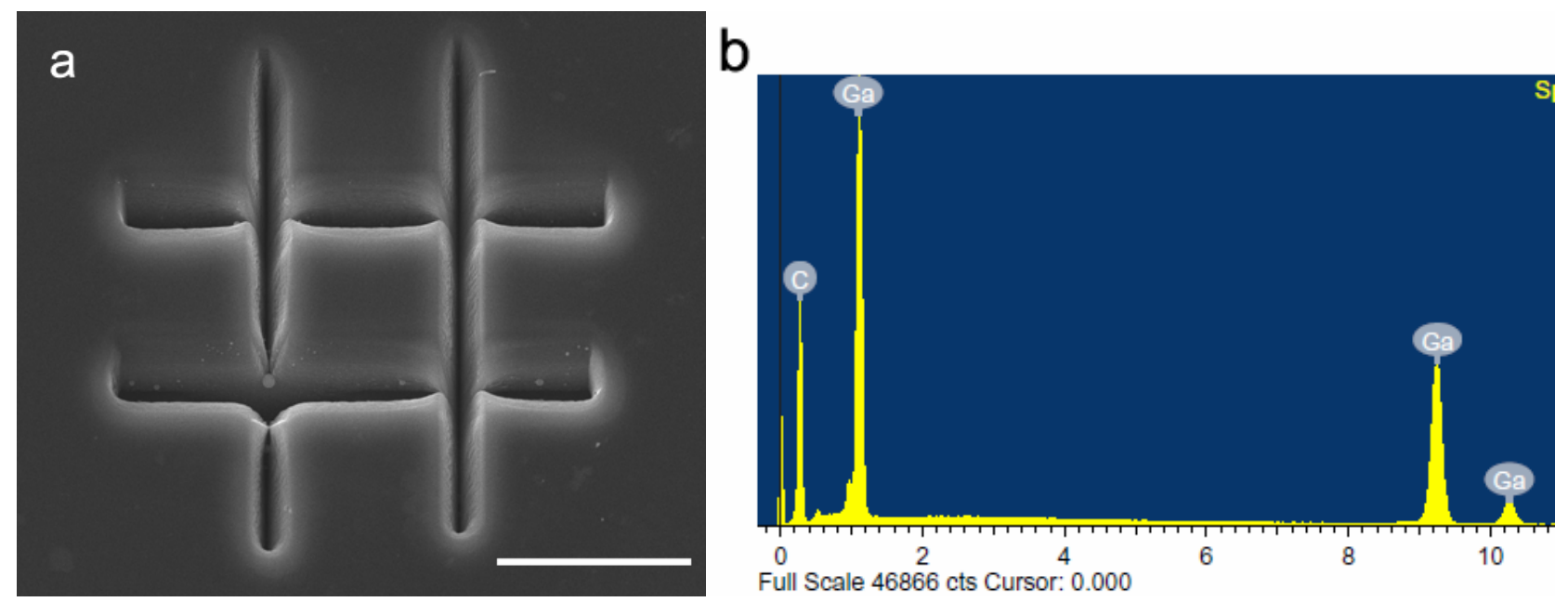

Figure 1. a) Sequentially etched linear patterns, starting with line A at $1 \mu \mathrm{m}$ x $50 \mu \mathrm{m}$ x $50 \mu \mathrm{m}$; then line B, C, and D, with identical dimensions; scale bar represents $20 \mu \mathrm{m}$. b) Elemental analysis of redeposited region along the intersection of lines.

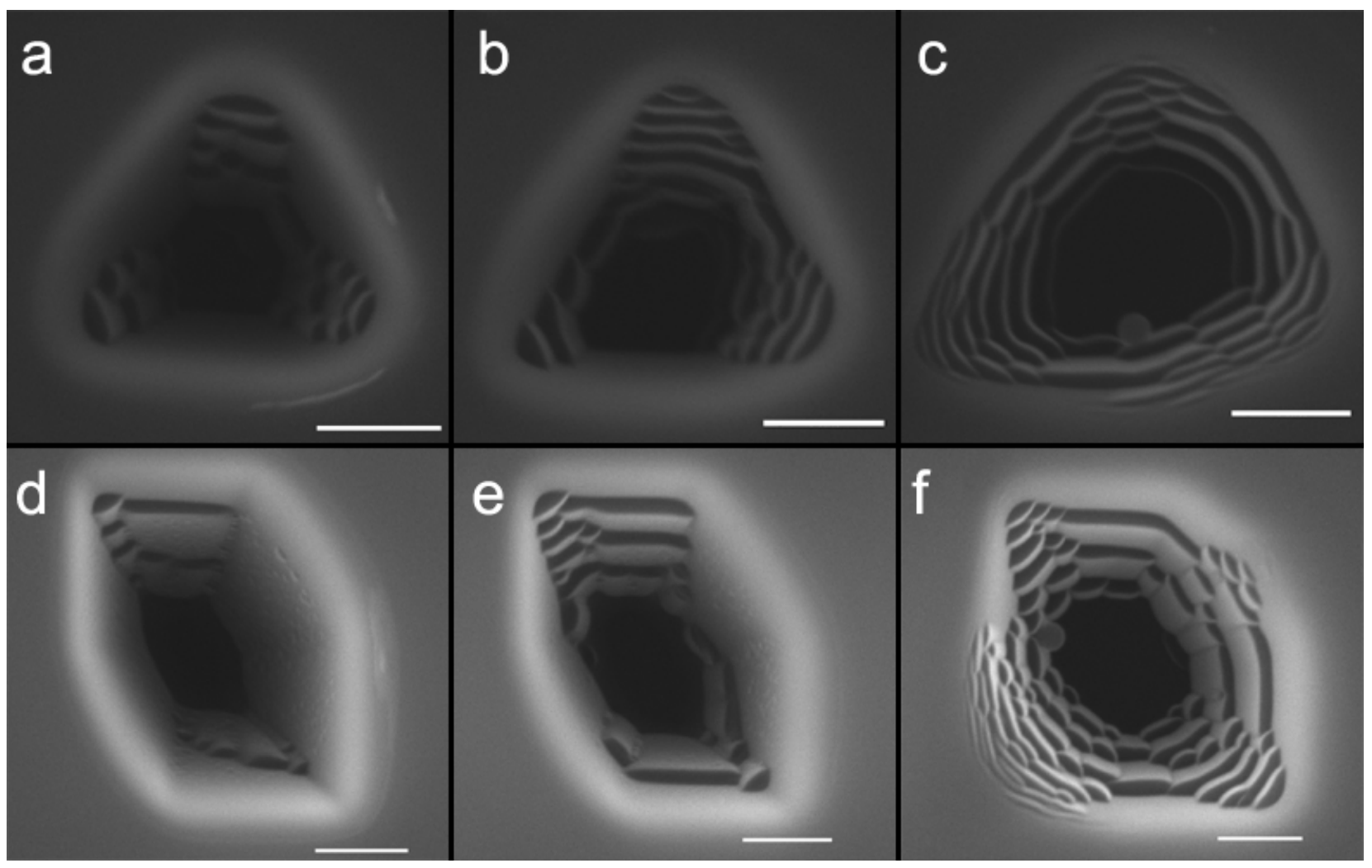

Figure 2. Scanning electron micrographs of triangular $(2 \mu \mathrm{m} \times 1.5 \mu \mathrm{m} \times 20 \mu \mathrm{m})$ patterns at varying currents: a) $3 \mathrm{nA}$, b) $7 \mathrm{nA}$, c) $20 \mathrm{nA}$; and square $(2 \mu \mathrm{m} \times 2 \mu \mathrm{m} \times 20 \mu \mathrm{m})$ patterns at: d) $3 \mathrm{nA}$, e) $7 \mathrm{nA}$, f) $20 \mathrm{nA}$. Scale bars represent $1 \mu \mathrm{m}$. 